\title{
Inhibitory Effects of BVAN08 on the Growth of Experimental Tumor Cell Lines Both in vivo and in vitro
}

\author{
Bo Zhang ${ }^{1,2}$, Sai Hư ${ }^{3}$, Lantao Liư ${ }^{4}$, Zi-Jian Yu ${ }^{5}$, Hua Guan², Lijing Geng ${ }^{1}$ and Ping-Kun Zhou ${ }^{2 *}$ \\ ${ }^{1}$ College of Food Science and Engineering, Jinzhou Medical University, Liaoning Province, 121000, PR China \\ ${ }^{2}$ Department of Radiation Toxicology and Oncology, Beijing Key Laboratory for Radiobiology (BKLRB), Beijing Institute of Radiation Medicine, 100850 Beijing, PR China \\ ${ }^{3}$ Institute for Environmental Medicine and Radiation Health, College of Public Health, University of South China, Hengyang, Hunan Province 421001, PR China \\ ${ }^{4}$ Beijing Institute for Occupational Disease Prevention and Treatment, 50 Yikesong Road, Xiangshan, Beijing, 100093, PR China \\ ${ }^{5}$ Department of Hepatobiliary Surgery, The First Affiliated Hospital, University of South China, Hengyang, Hunan Province 421001, PR China
}

\begin{abstract}
In order to study the mechanism of a novel vanillin derivative BVAN08, provide evidence and experimental data for developing it as a new potential anticancer drug. Hepatic cancer HepG2 cells and normal LO2 cells were used to investigate cytotoxicity of BVAN08. The MTT and colony-forming ability assays showed that BVAN08 significantly sensitized HepG2 cells to radiation rather than LO2 cells. Moreover, BVAN08 inhibited the growth of HepG2 cells in nude mice and exerted no effects on body weight and the number of the peripheral white blood cells. The immunohistochemistry results indicated that the DNA-PKcs expression the BVAN08 group tumor was lower than that of control group. BVAN08 obviously inhibits proliferation of HepG2 cells in vitro and in vivo supporting it as a promising anticancer drug candidate.
\end{abstract}

Keywords: Vanillin derivative; Apoptosis; DNA damage; DNA-PKcs; Antiproliferation

\section{Introduction}

As a natural phenolic compound, vanillin has been reported to have antioxidant and anti-mutagenic activities, and has also been proved to exert weakly inhibitory roles on the activities of DNA-PKcs (DNA-dependent protein kinase catalytic subunit) [1]. To obtain more information regarding the structure-activity relationship of vanillin derivatives, a series of vanillin derivatives were identified. A vanillin derivative BVAN08 (6-bromine-5-hydroxy-4-methoxybenzaldehyde) selected as a promising candidate compound. BVAN08 displayed obvious inhibitory activity on anti-proliferation, inhibited DNA-PKcs kinase activity and inactivated Akt in human Jurkat leukemia cells [2]. BVAN08 exhibited a potent antiproliferative effect on a broad spectrum of cancer cell lines, but it's antiapoptotic roles demonstrated a large variation on different cancer cell lines. BVAN08-induced cleavage and inactivation of DNA-PKcs was found to occur concurrently with a rapid destruction of $\mathrm{c}-\mathrm{Myc}$ oncoprotein [3]. Moreover, the induction of DNA damage and spindle disruption by BVAN08, which generates DNA double-stranded breaks and mitotic arrest [4].

DNA-dependent protein kinase catalytic subunit (DNA-PKcs), a key component involves in the non-homologous end joining (NHEJ) pathway of DNA double-strand breaks and has important role in protecting the stabilization of chromosome telomere [5,6]. Many researches indicated that protein levels of DNA-PKcs were highly expressed in many kinds of tumors. So DNA-PKcs was a potential therapeutic target to cure cancer [7]. It was also reported that inhibition of DNA-PKcs was a valid approach to increase the tumor cell killing of some anticancer agents such as cisplatin, Top II poisons and ionizing radiation [7-11].

Previously revealed that BVAN08, exhibited a potent antiproliferative effect on a broad spectrum of cancer cell lines, Herein we further confirmed the BVAN08's significantly antiproliferative effect on HepG2 cells but lower cytotoxic activity on $\mathrm{LO} 2$ cells. Meanwhile, our results also demonstrated that BVAN08 resulted in DNA-PKcs cleavage and DNA double-strand breaks. We further found that BVAN08 have the efficiency to induced apoptotic death. By means of molecular image system, we have found that BVAN08 obviously inhibited the growth of tumor in vivo.

\section{Materials and Methods}

\section{Chemicals and cell culture}

Vanillin derivative BVAN08 (6-bromine-5-hydroxy-4methoxybenzaldehyde) was provided by Dr. Lin Wang (Beijing Institute of Radiation Medicine). Chemical structures were shown previously [2]. Human liver cancer HepG2 cells and LO2 cells were cultured in DMEM medium supplemented with $10 \%$ fetal bovine serum in a humidified chamber at $37^{\circ} \mathrm{C}$ in $5 \% \mathrm{CO}_{2}$.

\section{Antibodies}

All antibodies were purchased commercially: anti-DNA-PKcs (H-163, Santa Cruz, CA), anti- $\beta$-actin (I-19-R, Santa Cruz, CA), antiRabbit IgG(H+L)/HRP (ZB-2301, Zhongshan, Beijing, China), antiMouse IgG(H+L)/HRP (ZB-2305, Zhongshan, Beijing, China), antitublin (ZM0438, Zhongshan, Beijing, China, anti- $\gamma$-tublin (ab11317, ABCAM), anti-phospho-Histon H2AX(ser139) (mouse monoclone IgG), Upstar (05-636, Rb IgG(H+L)/FITC-conjugated anti-rabbit IgG (ZF-0311, Zhongshan, Beijing, China, Mo IgG (H+L)/TRITCconjugated anti-mouse IgG (ZF-0313, Zhongshan, Beijing, China).

\section{MTT Assay}

Cells $\left(10^{4}\right.$ cells/well $)$ were seeded in $200 \mu$ of medium and cultured

*Corresponding author: Ping-Kun Zhou, Department of Radiation Toxicology and Oncology, Beijing Key Laboratory for Radiobiology (BKLRB), Beijing Institute of Radiation Medicine, 100850 Beijing, PR China, Tel: +861066931217; Fax: +861068183899; E-mail: zhoupk@nic.bmi.ac.cn/zhoupkek@yahoo.com.cn

Received July 29, 2017; Accepted August 24, 2017; Published August 29, 2017

Citation: Zhang B, Hu S, Liu L, Yu ZJ, Guan H, et al. (2017) Inhibitory Effects of BVAN08 on the Growth of Experimental Tumor Cell Lines Both in vivo and in vitro. J Carcinogene Mutagene 8: 305. doi: 10.4172/2157-2518.1000305

Copyright: @ 2017 Zhang B, et al. This is an open-access article distributed under the terms of the Creative Commons Attribution License, which permits unrestricted use, distribution, and reproduction in any medium, provided the original author and source are credited. 
at $37^{\circ} \mathrm{C}$ for $24 \mathrm{~h}$, then the medium was replaced with fresh media containing testing agents. After further $24 \mathrm{~h}$ incubation, $20 \mu \mathrm{l}$ of MTT (5 $\mathrm{mg} / \mathrm{ml}$ ) was added to each well and incubated for $4 \mathrm{~h}$. The medium was discarded and $150 \mu \mathrm{l}$ of DMSO was added to each well and incubated for $20 \mathrm{~min}$. The OD at $570 \mathrm{~nm}$ was measured and the cell growth inhibitory ratio was calculated via following formula and described with cell growth inhibitory curve. The half cell growth inhibitory concentration (IC50) was calculated with the curve. Cell Growth inhibitory ratio=[1(average absorbance of experimental group/average absorbance of contrast group)] $\times 100 \%$. The experiments were repeated thrice.

\section{Clonogenic survival}

The cells were trypsinized, counted, and diluted to certain concentrations. An appropriate number of cells $\left(3 \times 10^{2}\right.$ to $\left.1 \times 10^{4}\right)$ were plated into $60 \mathrm{~mm}$ diameter petri dishes in triplicate, and incubated in the culture medium containing different concentrations of BVAN08 for $24 \mathrm{~h}$, then continuously incubated in the growth medium without BVAN08. After total of 2 weeks culture, cells were fixed with methanol, stained with Giemsa solution, and colonies consisting of more than 50 cells were counted. Resulting survival plots were fitted. All experiments were repeated at 3 times and the mean values for each group were compared using Student's t-test at $\mathrm{P}<005$.

\section{Cell-cycle analysis}

HepG2 cells and LO2 cells were treated with different concentration BVAN08 for certain time, the cells were harvested and fixed with $75 \%$ ethanol. Cell were resuspended in PBS plus $0.1 \%$ saponine and $1 \mu \mathrm{g} / \mathrm{ml}$ RNase A (Sigma), incubated for $20 \mathrm{~min}$ at $37^{\circ} \mathrm{C}$, and stained with 25 $\mu \mathrm{g} / \mathrm{ml}$ propidium iodide(PI)(Sigma). Cell-cycle distribution was then evaluated by flow cytometry (>10,000 cells per sample).

\section{Apoptosis detection}

Cells were harvested after BVAN08 treatment for certain time. KGA212 kit was used to detect apoptosis. Washed in PBS and re-suspended in $500 \mu \mathrm{l}$ binding buffer at a concentration of $1 \times 10^{6}$ cells $/ \mathrm{ml}$. And then 5 $\mu \mathrm{l}$ of annexin-V-FIFC and $5 \mu \mathrm{l}$ PI was added. The tubes were incubated for $20 \mathrm{~min}$ at room temperature in the dark. Flow cytometric analysis was performed immediately after supravital staining. The amounts of early apoptosis and late apoptosis/necrosis were determined, respectively, as the percentage of Annexin V+/PI- or Annexin V+/PI+.

\section{Generation of stable cell lines which expressed GFP protein}

HepG2 cells were transfected with pEGFPN1 expression plasmid for stable expression of GFP protein. Transfection was performed using Lipofectamin 2000 according to manufacturer's instructions. Fortyeight hours later, cells were split in 1:10 in selection medium (complete medium with $0.5 \mathrm{mg} / \mathrm{mlG} 418$ ). After 3-weeks' selection, G418-resistant colonies were expanded in 24-well plates and maintained in medium supplement with $0.1 \mathrm{mg} / \mathrm{ml} \mathrm{G} 418$. The stable cell lines expressing GFP protein were screened by fluorescence microscope.

\section{Animal and experimental design}

Female BALB/c nude mice, 4-6 weeks old and weighing 18-20 g, were supplied by the laboratory Animal Center of the Academy of Military Medical Sciences. They were kept in autoclaved cage with polyester fiber filters to avoid contacting with the pathogens in $12 \mathrm{~h}$ light-dark cycle at $22-25^{\circ} \mathrm{C}$ and were fed with standard laboratory food and water ad libitum. Transplantable tumors (induced by HepG2GFP cells, subcutaneous inoculation of a mixture of $2 \times 10^{7}$ actively growing HepG2-GFP cells in $200 \mu \mathrm{l}$ PBS to the dorsal side of each nude mouse) were chopped into fragments (about $1.5 \mathrm{~mm}^{3}$ ), each of which was transplanted into the right axillary fossa of 24 nude mice. Palpable tumors of volume $100-200 \mathrm{~mm}^{3}$ were developed after 15 days and the mice were randomly divided into 4 groups (with 6 mice per group): negative control group; BVAN08 2, 5, and $10 \mathrm{mg} / \mathrm{kg}$ groups. The negative control group received $0.9 \%$ normal saline containing $1 \%$ DMSO. All of these drugs were injected intraperitoneally every day up to 15 days. Tumor size was measured once every 2 days in two perpendiculars and tumor volume (TV) was calculated using the formula: $\left(\mathrm{ab}^{2}\right) /^{2}$, where a and $\mathrm{b}$ refers to the longer and shorter dimensions, respectively. The body weight of the animals was measured three times a week at the same time as the tumor dimension measurement and the mortality was monitored daily. The tumor growth inhibition rate was calculated using the formula: inhibition rate $(\%)=($ mean negative control group - mean tumor weight of treatment group)/mean tumor weight of negative control group.

\section{Fluorescence imaging}

The tumor size was monitored by Berthold LB983 NightOwl System (NC100, Germany) in expression of EGFP. The excitation source is filtered using an HQ 470 band pass filter (Chroma Technology Corp, Rockingham, VT) and uniformly illuminates the field of view of the mouse. The emission spectrum is filtered using an HQ 525 band pass filter (Chroma Technology) to enhance the GFP fluorescence relative to the autofluorescence signal from endogenous tissue. The fluorescent images of the tumor were taken after tumor transplanted for 7 days, and at first day treatment immediately was taken image, and on days 4, 9, 13 days were totally taken image 3 times, after 15 days treatment we dislodge tumor and take image of fluorescence. The mice were sedated (50 mg/kg pentobarbital by i.p. injection), positioned in the light-tight chamber, and imaged with an exposure time of $100 \mathrm{~ms}$. And the data were analyzed by the WinLight 32 software supplied with the instrument.

\section{Immunohistochemistry analysis of DNA-PKcs}

The tumors of nude mice from one cell transplantation groups $(n=6)$ and control groups $(n=6)$ were used for immunohistochemistry after treatment period. To perform immunohistochemistry, the tumors were immersed in $10 \%$ neutral formalin, and postfixed at room temperature for $48 \mathrm{~h}$. The tumors were then embedded in paraffin. Paraffin sections $(2 \mu \mathrm{m})$ were obtained with an ultramicrotome (Leica, Germany) and attached to glass slides. The sections (a small portion of sections were dedicated to hematoxylin and eosin (HE) staining) were then incubated overnight at $4^{\circ} \mathrm{C}$ with DNA-PKcs (polyclonal antibody; Santa Cruz Biotechnology (H-163); 1:500) primary antibodies. After reaction with the primary antibodies, the specimens were washed 3 times with PBS for $5 \mathrm{~min}$ and incubated with the corresponding secondary antibodies (horseradish peroxidase (HRP) conjugated goat anti- rabbit IgG) for $20 \mathrm{~min}$ in a humid box in the dark at room temperature. Coloration was made with $3,3^{\prime}$-diaminobenzidine $(\mathrm{DAB})$ solution and the positive product was labeled brown. Slides were rinsed completely and nuclei were counterstained with hematoxylin. Subsequently, specimens were dehydrated and mounted with neutral resin and cover slips for histologic analysis. The cells whose cytoplasmic granules appear brown granules were regarded as positive cells, then, we selected five fields of vision that was magnified 400 times to count the number of positive cells in 100 cells: $<5 \%$ as negative $(-), 6 \%-25 \%$ as positive $(+), 26 \%-$ $50 \%$ as moderately positive $(++)$, and $>50 \%$ as highly positive $(+++)$. A cytoplasmic staining was considered nonspecific.

\section{Lencocyte counts}

At the end of treatment, nude mice were collected blood by vena 
Citation: Zhang B, Hu S, Liu L, Yu ZJ, Guan H, et al. (2017) Inhibitory Effects of BVAN08 on the Growth of Experimental Tumor Cell Lines Both in vivo and in vitro. J Carcinogene Mutagene 8: 305. doi: 10.4172/2157-2518.1000305

Page 3 of 7

then count peripheral blood leucocyte by complete blood count instrument.

\section{Results}

\section{Antiproliferative effect of BVAN08 on HepG2 cell lines}

Cell viability was assessed by MTT assay. HepG 2 cells were treated with BVAN08 for $4 \mathrm{~h}, 8 \mathrm{~h}, 12 \mathrm{~h}, 24 \mathrm{~h}$, and $48 \mathrm{~h}$. The results indicated that $40 \mu \mathrm{M}$ BVAN08 inhibited the proliferation of HepG2 cells and $80 \mu \mathrm{M}$ BVAN08 could obviously inhibit the proliferation of HepG2 cells in $24 \mathrm{~h}(\mathrm{p}<0.01)$. Moreover, $40 \mu \mathrm{M}$ BVAN08 also obviously inhibited cell proliferation at $48 \mathrm{~h}$ indicated that BVAN08 possessed potent anticancer activity $(\mathrm{p}<0.01)$, and the inhibition ratio was in a time-dependent manner of cell proliferation (Table 1). As normal liver cell line the effects of BVAN08 on LO2 cells were weak, even $80 \mu \mathrm{M}$ BVAN08 exerted no influence at $48 \mathrm{~h}$ which indicated the antiproliferative activity on $\mathrm{LO} 2$ cell lines was very minor (Table 2). In addition, we also compared the antiproliferation under various concentrations of BVAN08 at $48 \mathrm{~h}$ of HepG2 cells and LO2 cells. As showed in Figure 1a, antiproliferative effect of BVAN08 characterized by a dosedependent manner both on HepG2 and LO2 cells. The inhibition ratio of HepG2 cells was up to $80 \%$ (Figure 1b). The IC50 of BVAN08 was $32.6 \mu \mathrm{M}$, however on $\mathrm{LO} 2$ cells was $86.5 \mu \mathrm{M}$ (data not shown).

\begin{tabular}{|c|c|c|c|c|c|}
\hline \multirow{2}{*}{ Concentration $(\mu \mathrm{M})$} & \multicolumn{5}{|c|}{ Culture Time (h) } \\
\hline & 4 & 8 & 12 & 24 & 48 \\
\hline 0 & $0.443 \pm 0.007$ & & & & \\
\hline 1 & $0.492 \pm 0.085$ & $0.493 \pm 0.070$ & $0.473 \pm 0.070$ & $0.505 \pm 0.064$ & $0.479 \pm 0.044$ \\
\hline 5 & $0.462 \pm 0.055$ & $0.444 \pm 0.061$ & $0.421 \pm 0.043$ & $0.451 \pm 0.050$ & $0.408 \pm 0.064$ \\
\hline 10 & $0.452 \pm 0.072$ & $0.398 \pm 0.062$ & $0.403 \pm 0.064$ & $0.409 \pm 0.031$ & $0.362 \pm 0.013$ \\
\hline 20 & $0.406 \pm 0.058$ & $0.445 \pm 0.046$ & $0.510 \pm 0.049$ & $0.520 \pm 0.033$ & $0.495 \pm 0.185$ \\
\hline 40 & $0.500 \pm 0.064$ & $0.461 \pm 0.015$ & $0.404 \pm 0.086$ & $0.300 \pm 0.058^{*}$ & $0.231 \pm 0.055^{* *}$ \\
\hline 80 & $0.479 \pm 0.067$ & $0.428 \pm 0.057$ & $0.372 \pm 0.071$ & $0.180 \pm 0.032^{* *}$ & $0.119 \pm 0.015^{* *}$ \\
\hline
\end{tabular}

Table 1: The effect of vanillin derivative BVAN08 on proliferation of HepG2 cells (OD).

\begin{tabular}{|c|c|c|c|c|}
\hline \multirow{2}{*}{ Concentration $(\mu \mathbf{M})$} & \multicolumn{3}{|c|}{ Culture Time (h) } \\
\cline { 2 - 5 } & 4 & 8 & 12 & 24 \\
\hline 0 & $0.419 \pm 0.005$ & & & \\
\hline 1 & $0.448 \pm 0.078$ & $0.418 \pm 0.056$ & $0.426 \pm 0.052$ & $0.446 \pm 0.039$ \\
\hline 5 & $0.420 \pm 0.061$ & $0.421 \pm 0.065$ & $0.427 \pm 0.065$ & $0.443 \pm 0.071$ \\
\hline 10 & $0.420 \pm 0.056$ & $0.451 \pm 0.059$ & $0.467 \pm 0.044$ & $0.467 \pm 0.421$ \\
\hline 20 & $0.412 \pm 0.073$ & $0.456 \pm 0.061$ & $0.459 \pm 0.012$ & $0.429 \pm 0.059$ \\
\hline 40 & $0.429 \pm 0.056$ & $0.409 \pm 0.021$ & $0.402 \pm 0.070$ & $0.365 \pm 0.059$ \\
\hline 80 & $0.421 \pm 0.052$ & $0.397 \pm 0.063$ & $0.407 \pm 0.061$ & $0.064 \pm 0.040$ \\
\hline
\end{tabular}

Table 2: The effect of vanillin derivative BVAN08 on proliferation of LO2 cells (OD).

a

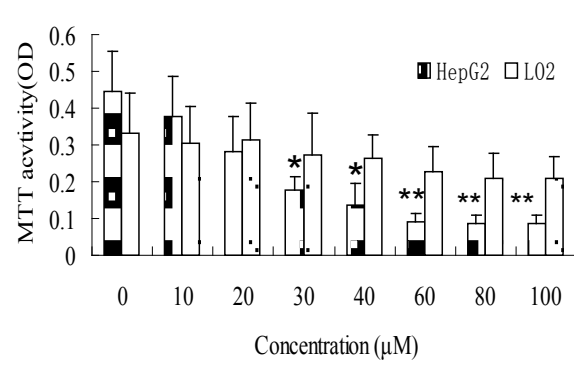

b

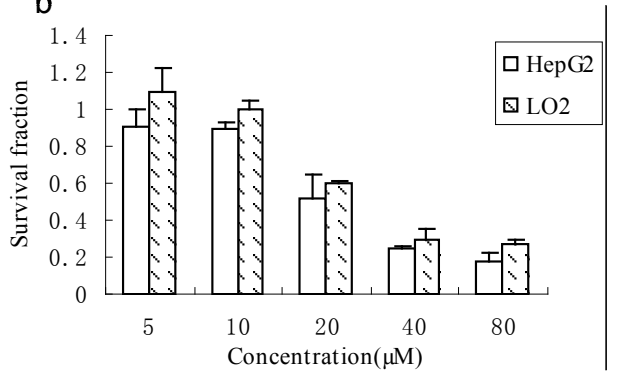

C

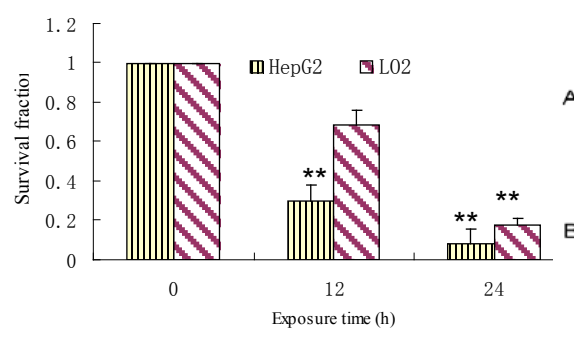

d

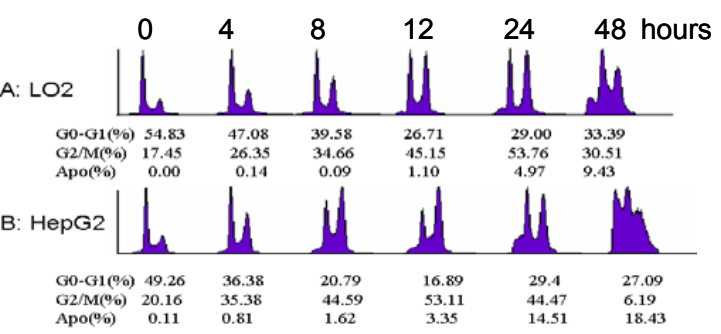

Figure 1: Effects of BVAN08 on proliferation of LO2 and HepG2 cells. a. Comparison of antiproliferation of BVAN08 on HepG2 cells and LO2 cells by MTT measurement. b. Inhibition ratio curves of HepG2 cells and LO2 cells after treated with BVAN08. c. Clonogenic survival of LO2 and HepG2 cells after treated with BVAN08. d. Apoptosis and cell cycle changes induced by $40 \mu \mathrm{M}$ BVAN08 detected for different time $(0,4,8,12,24,48 \mathrm{~h})$ by flow cytometry. 
Citation: Zhang B, Hu S, Liu L, Yu ZJ, Guan H, et al. (2017) Inhibitory Effects of BVAN08 on the Growth of Experimental Tumor Cell Lines Both in vivo and in vitro. J Carcinogene Mutagene 8: 305. doi: 10.4172/2157-2518.1000305

The antiproliferative activity of BVAN08 was detected by clone forming analysis experiment. The LO2 and HepG2 cells were pretreated by $40 \mu \mathrm{M}$ BVAN08 for 12 and $24 \mathrm{~h}$, after 15 days we analyzed the clone formation. Our results indicated that $40 \mu \mathrm{M}$ BVAN08 could inhibit HepG 2 cells' proliferation of at $12 \mathrm{~h}$ but have no effect on the LO2 cells. Even though the survival rate of LO2 cells was also degraded, it still much higher than that of HepG2 cells (Figure 1c). We indicated that BVAN08 have antiproliferative effect on HepG2 cell lines, but small cytotoxicity on LO2 cells.

Flow cytometry was performed on BVAN08-treated HepG2 cells and LO2 cells for cell-cycle analysis. The results revealed that BVAN08 induced obviously $\mathrm{G} 2 / \mathrm{M}$ arrest and in a time-dependent manner. After $48 \mathrm{~h}$ the G2/M phase cells of HepG2 cells were decreased. In addition, there emerged a great number of aneuploid cells in HepG2 cells after $40 \mu \mathrm{M}$ BVAN08 treated (Figure 1d).

\section{BVAN08-induced apoptosis in HepG2 cells}

The apoptosis of HepG2 cells induced by BVAN08 was firstly detected by means of fluorescent dye staining. In this assay, the nuclei of apoptotic cells was stained bright blue with Hoechst 33342 due to chromatin condensation, and the necrosis cells was stained bright red with PI (Figure 2a). The time-dependent induction of necrosis at 60 $\mu \mathrm{M}$ BVAN08 treatment was observed, but the apoptosis was obviously higher as compared to control. Results of apoptosis and necrosis after $60 \mu \mathrm{M}$ BVAN08 treatment for different times were shown in Figure $2 \mathrm{~b}$.

BVAN08-elicited apoptotic cell death of HepG2 cells was also demonstrated by flow cytometry. The early apoptotic cells were marked by Annexin V-FITC (Figure 2c). The results indicated that BVAN08 induced apoptosis in HepG2 cells; the percentage of apoptosis was obviously increased after $72 \mathrm{~h}$ treatment (Figure 2d). Our results indicated that BVAN08 inhibited the growth of HepG2 cells, at least in part, by induction of apoptosis.

\section{Fluorescence imaging and in vivo tumor growth}

HepG2 cells stabilized expressed GFP protein were selected after G418 screening. Under normal light microscopy, the HepG2 cells expressed GFP protein were the same as ordinary HepG2 cells in morphous. Under fluorescent light, cells appeared green demonstrating the cells expressed GFP protein and after 20 generation without G418 screening (data not shown).

The Nightowl molecular light imaging system was used for fluorescent detection of tumor after hypodermic inoculation 7 days. The fluorescence intensities defined as photon per second per millimeter squared $\left(\mathrm{ph} / \mathrm{s} / \mathrm{mm}^{2}\right)$ in the tumor. A strong signal showed up on the images 7 days after hypodermic inoculation tumor structure, which suggested that the tumor cells grow rapidly. During the following 13 days, fluorescence upgraded rapidly in control group and it went up slightly in $10 \mathrm{mg} / \mathrm{kg}$ group. In the last day of treatment, the tumors in both control group and $10 \mathrm{mg} / \mathrm{kg}$ group seems to necrosis (Figure 3a). The fluorescence image of tumor in vitro showed that photons in all the three experiment groups were lower than the control group (Figures $3 \mathrm{~b}$ and $3 \mathrm{c})$.

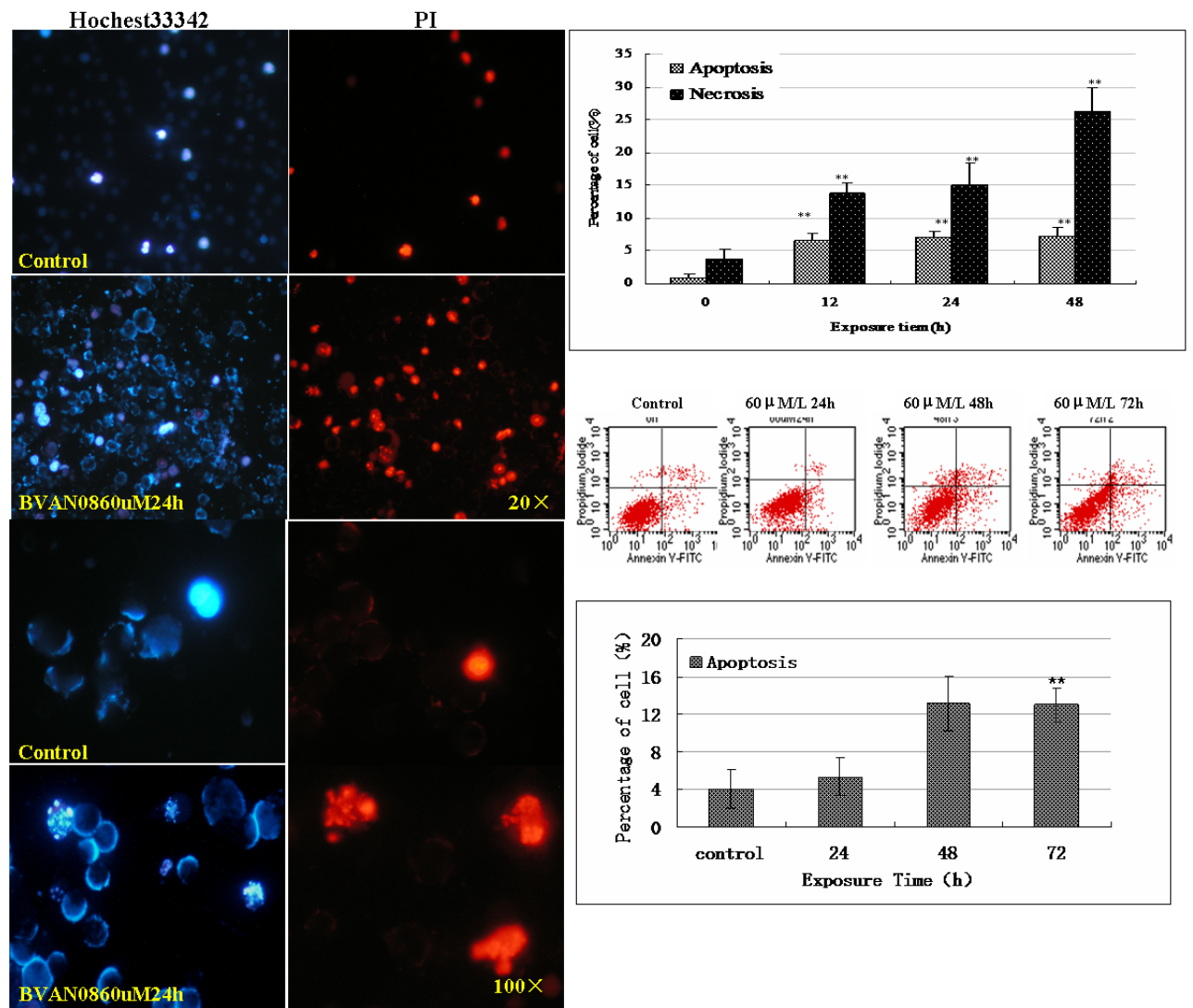

Figure 2: Induction of apoptosis by BVAN08 on HepG2 cells. a. Morphological characteristics of apoptosis displayed under fluorescence microscopy. b. The percentage of apoptosis and necrosis after $60 \mu \mathrm{M}$ BVAN08 treated for different times. c. Detection of BVAN08-induced apoptosis by flow cytometry. d. The percentage of apoptosis and necrosis after $60 \mu \mathrm{M}$ BVAN08 treated for different times. 

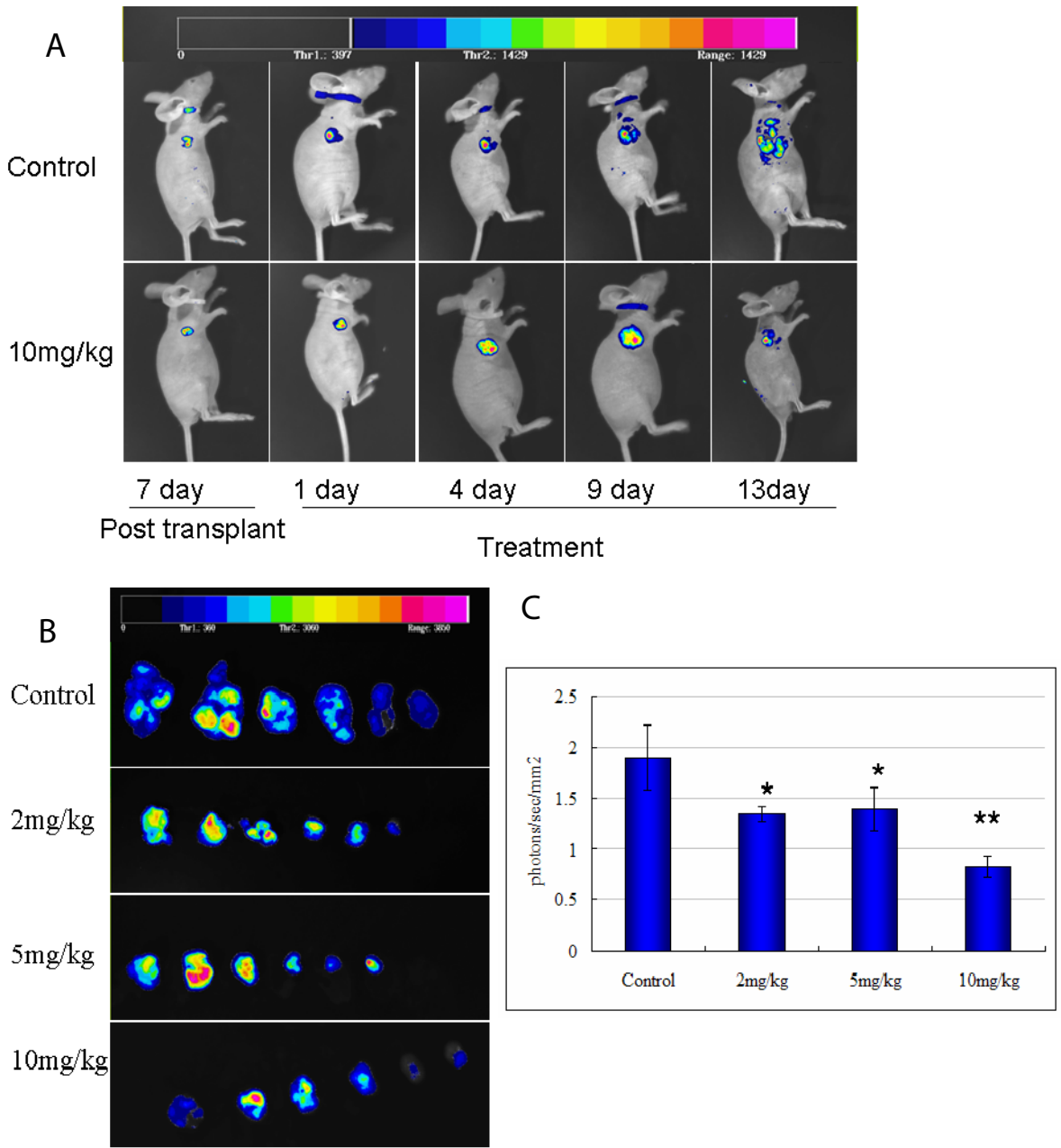

Figure 3: Molecular light imaging system to detected tumor. a. In vivo optical imaging of hypodermi tumor. b. In vitro optical imaging tumor. c. Quantitative of tumor photons.

\section{BVAN08 inhibits tumor growth in nude mice}

The results showed no significant variation in body weight after 15 days of treatment with BVAN08 (Figure 4a), suggesting that BVAN08 produced no significant non-tumor toxicity in tumor-bearing mice.

However, the tumor volume also significantly decreased when compared with non-treated with BVAN08 (Figure $4 \mathrm{~b}$ ). In addition, the average weights of tumors treated with BVAN08 at 2,5 , and $10 \mathrm{mg} / \mathrm{kg}$ were $220.4 \mathrm{mg}, 191.0 \mathrm{mg}$, and $229.9 \mathrm{mg}$ respectively, versus $531.9 \mathrm{mg}$ of negative control tumors, which correspond to $58.5 \%, 64.0 \%$, and $56.7 \%$ of inhibition (Figure $4 \mathrm{c})(\mathrm{p}<0.01)$. The peripheral blood leucocyte had no difference in control group and BVAN08 treated group (Figure $4 \mathrm{~d}$ ). These results suggested that BVAN08 was efficiently capable of inhibiting the tumor growth in vivo and no obvious side effects were found.

HE staining showed the nucleus of cells was greatly different and morphous rugosity, nuclus divisions were abnormal indicated that the structures were malignant tumor.

One important requirement in order to ensure a successful therapy using BVAN08 is that DNA-PKcs is low expressed in tumor structure. IHC studies indicating that DNA-PKcs was mainly moderately positive expressed in BVAN08 treated group. However, strong expression was found in control group, with highly positive expression of DNA-PKcs tumor structure (Figure 4e).

\section{Discussion}

The adriamycin is majorly used to cure liver cancer clinically but it has a lot of adverse effects, for this reason, it is important to develop new antineoplastic agents which kill tumor cells specificity and have no harm to normal hepatic cells [12]. The antiproliferative effect of BVAN08 on various cancer cell lines has been investigated [3] and we have previously reported that BVAN08 induced apoptosis of Human Jurkat leukemia cells [2]. In present study, we demonstrated that BVAN08 inhibited proliferation of HepG2 cells, and $40 \mu$ M BVAN08 treated for $24 \mathrm{~h}$ could obviously inhibit the growth of HepG2 cells. In contrast, even $80 \mu \mathrm{M}$ BVAN08 did not have obvious effect after $48 \mathrm{~h}$ incubation. The results of clone-formation also indicated that BVAN08 have antiproliferative effects on HepG2 cells but small marginal effects on LO2 cells. Although BVAN08 exhibited very potent cytotoxicity towards HepG2 cells by MTT and clon-formation, it did not exhibited very potent cytotoxicity towards normal human hepatocyte cells LO2, suggesting its tumor-selective growth inhibitory effect.

Mammalian cells initiate cell cycle arrest at different phases of the cell cycle in response to various forms of genotoxic stress to allow time 


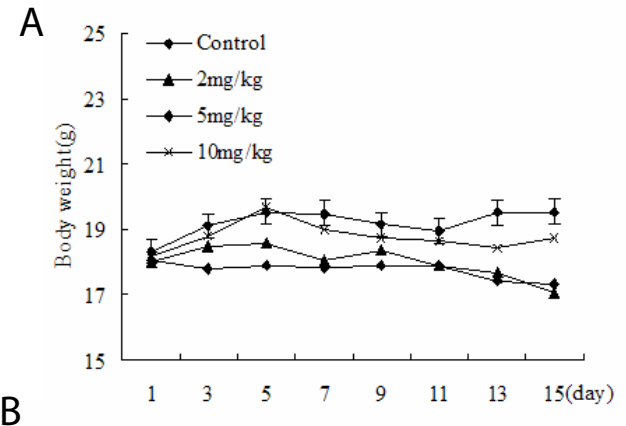

B

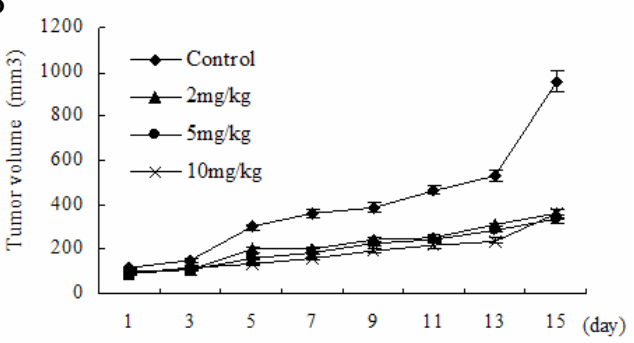

e

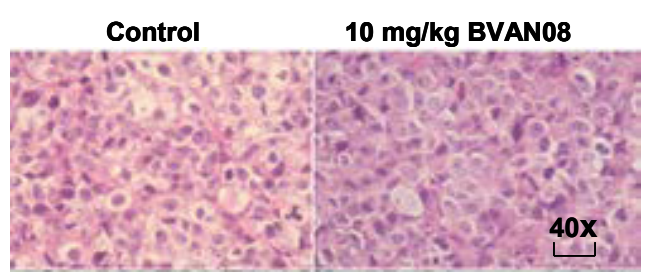

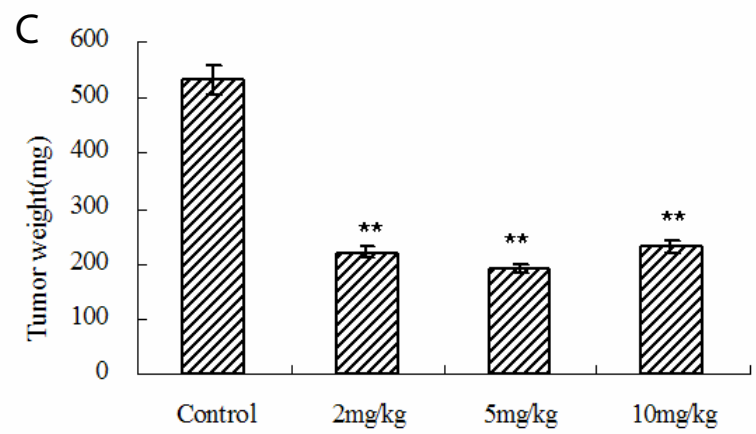

D
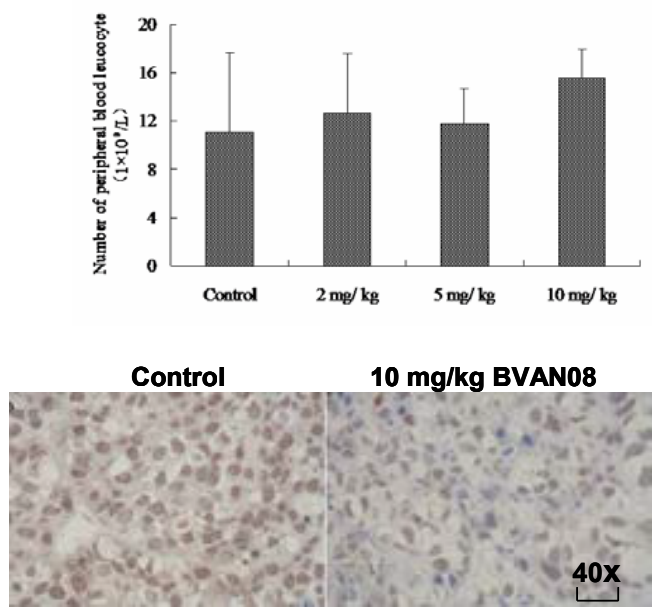

Figure 4: The in vivo anti-tumor effect of BVAN08 on athymic nude mice bearing HepG2 cells subcutaneously was studied. a. Body weight of control and BVAN08 treatment group. b. Tumor volume of control BVAN08 treatment groups. Tumor volume was measured once every 2 days. c. The weight of tumor of control BVA08 treatment groups. After nude mice were treated for 15 days, the tumors were isolated and weighed. ${ }^{*} \mathrm{P}<0.05$ and ${ }^{* *} \mathrm{P}<0.01$ compared with control. d. The peripheral blood leucocyte of control and BVAN08 treatment group. e. H\&E stain to identify tumor of HepG2 cell and immunohistochemical analysis of DNA-PKcs.

for DNA repair, and thus preserving their genomic integrity. In this study we examined the cell cycle by flow cytometry, and we observed a dramatic accumulation of $\mathrm{G} 2 / \mathrm{M}$ population in BVAN08-treated HepG2 cells and LO2 cells. The G2/M arrest of HepG2 cells were decreased after BVAN08-treatment for $48 \mathrm{~h}$, the main reason was that a number of cells died after so long time arrest, and accumulation of subG1 population of cells in HepG2 cells was higher than that of LO2 cells. Consequently, the BVAN08-induced HepG2 cells apoptosis were detected by means of fluorescent and flow cytometry, and apoptosis was characterized by Annexin-V staining. Our results showed that BVAN08 could dose-dependently induce apoptosis. Many researchers reported that some antitumor drugs induced a lot of kinds of cell death such as apoptotic, mitotic catastrophe, autophagy, and necrosis [13]. Our study showed not so much apoptosis in BVAN08-treated HepG2 cells, but the inhibition ration was up to $80 \%$, so we supposed that BVAN08 may induce another type of cell death.

A super cooled charge coupled device (CCD) camera within the imaging systems is capable of detecting low quantities of light from beneath the tissue [14]. This technology provides an alternative method to histological evaluation to determine the location of tumor cells. Utilizing the fluorescence of EGFP expressed in the cells, we were able to demonstrate distribution of tumor cells. Quantification of cell growth was accomplished using the molecular light imaging system. These findings demonstrate that GFP-transfected cells may be useful for imaging studies of superficial tumors where both excitation and emission wavelengths are able to penetrate tissue.

The fluorescence image of tumor in vitro also showed up that BVAN08 inhibit tumor growth, suggesting that BVAN08 had anticancer effect. The results from animal experiments also showed that after 15 days of treatment with BVAN08, no significant variation in body weight and peripheral blood leucocyte counts were observed, suggesting that BVAN08 did not produce significant non-tumor toxicity in tumor-bearing mice. We demonstrated the inhibition of proliferation of HepG2 cell growth in vivo with a corresponding reduction in the tumor volume and weight of xenografted tumor in nude nice with BVAN08 treatment. All these results show that BVAN08 is a potentially promising anti-cancer drug candidate with low toxicity and very little side effects. DNA double strand break (DSB) is a major threat to cell survival and genomic integrity, and it is also a major lesion signal for eliciting apoptosis and cell cycle arrest [15]. The catalytic subunit of the DNA-dependent protein kinase (DNA-PKcs) has a critical role in double-strand break repair via nonhomologous end-joining and regulates cellular responses to DNA double strand breaks [16]. In immunohistochemical studies, DAN-PKcs positive cells were detected at a high frequency in tumor tissues of control group, but low in 10 $\mathrm{mg} / \mathrm{kg}$ treated group. These results suggested that BVAN08 inhibited tumor growth in tumor-bearing mice by down-regulating expression of DAN-PKcs protein expression in tumor tissues of nude mice. BVAN08 
Citation: Zhang B, Hu S, Liu L, Yu ZJ, Guan H, et al. (2017) Inhibitory Effects of BVAN08 on the Growth of Experimental Tumor Cell Lines Both in vivo and in vitro. J Carcinogene Mutagene 8: 305. doi: 10.4172/2157-2518.1000305

might decrease the adverse reaction and improve the efficacy of cancer treatment.

In summary, our results showed that BVAN08 could inhibit the process of tumorigenesis through DNA-PKcs, and indicated that BVAN08 remarkably exerted potent inhibitory effects on the HepG2 cell growth by inducing apoptosis. These results suggested that BVAN08 could be developed as a promising chemotherapeutic agent in liver cancer therapy in the future.

\section{Acknowledgments}

This work was supported by Chinese National Natural Science Foundation (Grants No. 81372925, 31370843, 81530085) and the foundation of jinzhou medical school.

\section{References}

1. Stephen D, Peter K (2003) Vanillins-a novel family of DNA-PK inhibitors. Nucliec Acids Res 31: 5501-5512.

2. Yu-Qian Y, Qin-Zhi X, Wang L, Sui J, Bai B, et al, (2006) Vanillin derivative 6-bromine-5-hydroxy-4- methoxybenzaldehyde-elicited apoptosis and G2/M arrest of Jurkat cells proceeds concurrently with DNA-PKcs cleavage and Akt inactivation. Int J Oncol 29: 1167-1172.

3. Yan Y, Bo Z, Wang L, Xie Y, Peng T, et al. (2007) Induction of apoptosis and autophagic cell death by the vanillin derivative 6-bromine-5-hydroxy-4methoxybenzaldehyde is accompanied by the cleavage of DNA-PKcs and rapid destruction of c-Myc oncoprotein in HepG2 cells. Cancer Letters 252: 280-289.

4. Zhang, Bo H, Hua G, Shi-Meng Z, Qin-Zhi X, et al. (2011) Proteomic profiling revealed the functional networks associated with mitotic catastrophe of HepG2 hepatoma cells induced by 6-bromine-5-hydroxy-4-methoxybenzaldehyde. Toxicol Appl Pharmacol 252: 307-317.

5. Burma S, Chen DJ (2004) Role of DNA-PK in the cellular response to DNA double-strand breaks. DNA repair 3: 909-918.
6. Wang S, Guo M, Ouyang H, Li X, Cardo CC, et al. (2000) The catalytic subunit of DNA-dependent protein kinase selectively regulates p53-dependent apoptosis but not cell-cycle arrest. Proc Natl Acad Sci 97: 1584-1588.

7. Willmore E, Caux S de, Sunter NJ, Tilby MJ, Jackson GH, et al. (2004) A novel DNA dependent protein kinase inhibitor, NU7026, potentiates the cytotoxicity of topoisomerase II poisons used in the treatment of leukemia. Blood 103: 4659-4665.

8. Hoeijmarkers JH (2001) Genome maintenance mechanisms for preventing cancer. Nature 411: 366-374.

9. Collis SJ, Swartz MJ, Nelson WG, De Weese TL (2003) Enhanced radiation and chemotherapy-mediated cell killing of human cancer cells by small inhibitory RNA silencing of DNA repair factors. Cancer Res 63: 1550-1554.

10. An J, Xu QZ, Sui JL, Bai B, Zhou PK (2005) Downregulation of c-myc protein by siRNA-mediated silencing of DNA-PKcs in HeLa cells. Int J Cancer 117: 531-537.

11. An J, Xu QZ, Sui JL, Bai B, Zhou PK (2005) Silencing of DNA-PKcs alters the transcriptional profile of certain signal transduction genes related to proliferation and differentiation in HeLa cells. Int J Mol Med 16: 455-462.

12. Lee TK, Man K, Ho JW, Sun CK, Ng KT, et al. (2004) FTY720 induces apoptosis of human hepatoma cell lines through PI3-K-mediated Akt dephosphorylation. Carcinogenesis 25: 2397-2405.

13. Zhan X, John X, Thomas JS, Haiying Z (2006) Differential roles of checkpoin kinase 1 , checkpoint kinase 2 , and mitogen-activated protein kinase-activated protein kinase 2 in mediating DNA damage-induced cell cycle arrest: implications for cancer therapy. Mol Cancer Ther 5: 1935-1943.

14. Collis SJ, DeWeese TL, Jeggo PA, Parker AR (2005) The life and death of DNA-PK. Oncogene 24: 949-961.

15. Meek K, Gupta S, Ramsden DA, Lees-Miller SP (2004) The DNA-dependent protein kinase: the director at the end. Immunol Rev 200: 132-141.

16. Paull TT, Rogakou EP, Yamazaki V, Kirchgessner CU, Gellert M, et al. (2000) A critical role for histone $\mathrm{H} 2 \mathrm{AX}$ in recruitment of repair factors to nuclear foci after DNA damage. Curr Biol 10: 886-895. 